\title{
Skin, fascias, and scars: symptoms and systemic connections
}

This article was published in the following Dove Press journal:

Journal of Multidisciplinary Healthcare

28 December 2013

Number of times this article has been viewed

\author{
Bruno Bordoni' \\ Emiliano Zanier ${ }^{2}$ \\ 'Rehabilitation Cardiology Institute \\ of Hospitalization and Care \\ with Scientific Address, S Maria \\ Nascente Don Carlo Gnocchi \\ Foundation. CRESO Osteopathic \\ Centre for Research and Studies, \\ ${ }^{2}$ EdiAcademy, Milano, Italy. CRESO \\ Osteopathic Centre for Research and \\ Studies
}

\begin{abstract}
Every element or cell in the human body produces substances that communicate and respond in an autocrine or paracrine mode, consequently affecting organs and structures that are seemingly far from each other. The same also applies to the skin. In fact, when the integrity of the skin has been altered, or when its healing process is disturbed, it becomes a source of symptoms that are not merely cutaneous. The skin is an organ, and similar to any other structure, it has different functions in addition to connections with the central and peripheral nervous system. This article examines pathological responses produced by scars, analyzing definitions and differences. At the same time, it considers the subcutaneous fascias, as this connective structure is altered when there is a discontinuous cutaneous surface. The consequence is an ample symptomatology, which is not limited to the body area where the scar is located, such as a postural or trigeminal disorder.
\end{abstract}

Keywords: fascia, scarring, osteopathic, skin, scar

\section{Introduction: definition of skin and fascia}

The integument is composed of the epidermis and the dermis, which derive from different embryological sheets. The epidermis is the surface epithelium that originates in the ectoderm, meaning it is part of the structures that are in contact with the outside world. ${ }^{1,2}$ Among the other structures derived from the ectoderm, we identify the central and peripheral nervous system, the pituitary gland, the dental epithelium, and the mammary gland. ${ }^{3-6}$ Here we can find not only keratinocytes (which represent the first immune barrier, as they act as sentinels) but also melanocytes and immune cells (such as the Langerhans cells and the T-lymphocytes). ${ }^{7,8}$ There are also tactile cells, which are differentiated for selective touch. ${ }^{9}$

The dermis originates in the mesoderm, where, among other things, the connective tissue, bone, cartilage, blood, and their relevant organs are found. ${ }^{10-12}$ The dermis supports the epidermis and nourishes it. ${ }^{13}$ Numerous lymphatic and vascular vessels go through it, as well as different nerve endings, which can be free, as in the epidermis, or encapsulated in complex structures. ${ }^{9,13,14}$

The skin, with its $1.8 \mathrm{~m}^{2}$ surface, is one of the largest organs of the human body and is the one most exposed to the environment. ${ }^{13}$ It is subject to a continual exchange of information, not just tactile but also concerning light and liquids. Therefore, we can reasonably affirm that it is always electrically active. ${ }^{13-15}$ The skin sends and receives information to the entire body, although with different intensities depending on the location. ${ }^{16}$ For instance, the electrical activity of the dermis reflects its sympathetic sudomotor cholinergic function, which brings about continuous changes in the electrical
Correspondence: Bruno Bordoni Rehabilitation Cardiology IRCCS, S Maria Nascente Don Carlo Gnocchi Foundation, via Capecelatro 66, Milano, Italy

Tel +3902408182

$\mathrm{Fax}+3496300617$

Email bordonibruno@hotmail.com 
conduction property of the skin, depending on external and internal stimuli. ${ }^{17}$ To make another example, the mechanoreceptors of the skin always give information on posture, using low-threshold mechanosensitive afferents. ${ }^{18,19}$ Therefore, the skin is continuously developing. It is a mistake to think of the cutaneous surface as something unchangeable; on the contrary, it is always changing and directly participates in the homeostasis of the human body.

Beneath the dermis, there is an adipose layer, which also derives from the mesoderm. ${ }^{20}$ Beneath the adipose layer, we find the so-called fascia. The fascia should be regarded as a connective sheet that covers various areas by perfectly adhering to them like velcro, composed of irregularly arranged collagen fibers that are markedly different from the regularly arranged collagen fibers recognizable in tendons, ligaments, or aponeurotic sheets. ${ }^{21}$ The fascia surrounds and connects every muscle, even the tiniest myofibril, bones, nerves, and every single organ, forming a fascial system and bodily continuity. ${ }^{22-24}$ Embryologically, the fascia derives from the mesoderm, being the continuation of the connective tissue. ${ }^{24}$ The fascial system consists of several layers, each characterized by different direction and thickness, which are constantly and jointly communicating and exchanging information. The fascia is the philosophy of the body, meaning each body region is connected to another, whereas osteopathy is the philosophy of medicine: the entire human body must work in harmony.

\section{Definition of scar and endorsed hypotheses}

There are four main stages in skin healing: hemostasis, inflammation, proliferation, and remodeling. ${ }^{15}$ The healing process of the skin surface begins with the lesion, when the bleeding conveys the blood elements in the area of the injury (blood platelets, fibrin, fibronectin, glycoprotein), trying to produce a parallel vasoconstriction. ${ }^{15}$ The blood platelets come in contact with the exposed collagen and with other elements of the extracellular matrix. ${ }^{15}$ This contact induces the release of important growth factors (transforming growth factor-beta [TGF- $\beta$ ] and platelet-derived growth factor [PDGF]), whereas coagulants begin the reconstitution process. ${ }^{25}$ Coagulation belongs to the first reconstitution stage of the injured tissue, hemostasis. ${ }^{15}$ This process results in a deposit of fibrin and other similar substances, which represents a provisional matrix of successive healing events. ${ }^{15}$ The growth factors, such as TGF- $\beta$ and PDGF, are the most important cytokines that initiate the second stage of the skin healing process; namely, inflammation. ${ }^{26,27}$ PDGF produces the chemotaxis (ie, addressing movements toward a specific stimulus) of other elements of the process, such as neutrophils, macrophages, fibroblasts, and smooth muscle cells. ${ }^{15,27}$ The first cytokine, in contrast, attracts other macrophages and induces them to secrete further cytokines, controlling the action of the PDGF along with the production/secretion of collagen and of the relevant enzymes degrading the collagen. ${ }^{15}$ Within 24 hours of the lesion, inflammation is increased by neutrophils, which enter the lesion and clean it of foreign matter. ${ }^{15}$ This action can even last more than a week. ${ }^{15}$ The mastocytes, which secrete various substances such as leukotrienes, interleukins, and other enzymes, along with the neutrophils, are responsible for the symptoms of inflammation and vasodilatation: redness, heat, swelling, and pain. ${ }^{15}$ Other substances such as monocytes are activated within 2 days. ${ }^{15}$ They indicate the beginning of a subsequent overlapping stage; namely, proliferation. Therefore, once the wound has been cleaned, within 8-14 days from the injury, the third healing stage begins, involving the migration of the fibroblasts toward the provisional extracellular matrix made of fibrin and collagen. ${ }^{15}$ As this stage proceeds, the release of TGF- $\beta$ produced by different groups of cells controls the numerous functions of the fibroblasts. ${ }^{15,26,27}$

As the collagen increases (it is important to reinforce the wound), other substances such as the enzymes degrading the collagen decrease. ${ }^{15}$ At the beginning, the rate of collagen

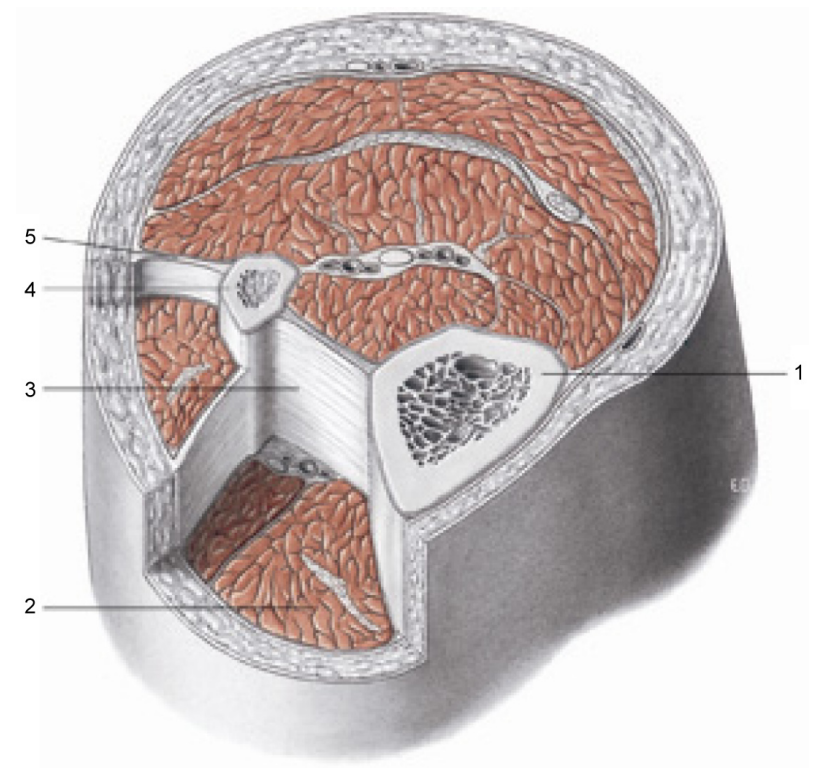

Figure I Transverse section at the level of the upper third of the leg. The fascia is the philosophy of the body, meaning each body region is connected to another, whereas osteopathy is the philosophy of medicine: the entire human body must work in harmony. Reproduced with permission Anastasi et al. AA VV, Anatomia dell'uomo, 4 ed, Edi.ermes, Milano [Human Anatomy]. ${ }^{114}$

Notes: I, tibia; 2, muscular loggia; 3 , interosseous membrane; 4, fibula; 5 , intermuscular septum. All tissues are enveloped by fascial continuity. 


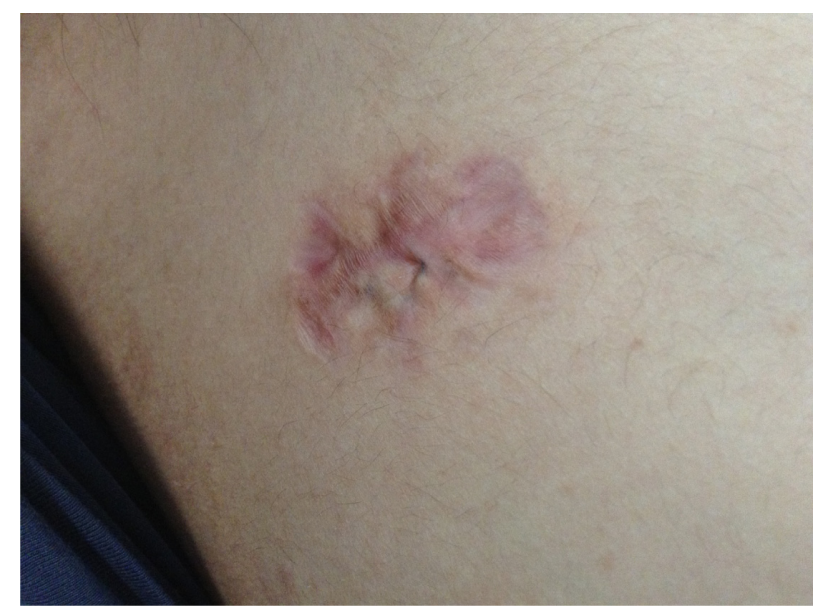

Figure 2 The photo shows atrophic scar on the shoulder.

Note: The atrophic scar appears as a cutaneous depression.

production exceeds the decrease of other substances. ${ }^{15}$ The fibroblasts, which are stimulated by the different growth factors, are divided into myofibroblasts comparable with smooth muscle cells (they hold a protein, which is the alpha smooth muscle actin). ${ }^{15,26}$ These cells can increase the traction

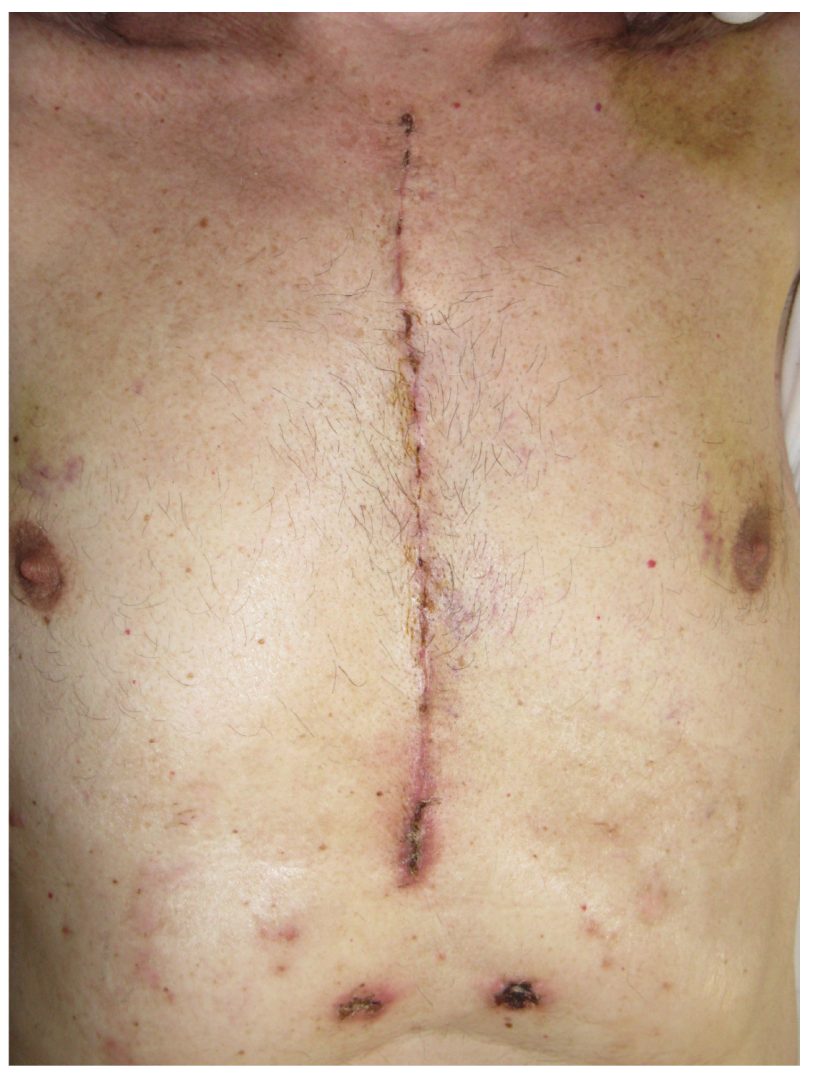

Figure 3 Intervention of sternotomy after cardiac surgery. There is a high percentage of risk that the scar could develop into a pathological scar.

Note: When the dermis and the fascia are affected by scars, these structures are altered, and their function and capacity of interaction with the external and internal environment are lacking. force, and thus they contract and reduce the open area of the lesion. ${ }^{15}$ After their contraction, they begin their apoptosis and gradually disappear. ${ }^{15}$ The concurrent breaking of the provisional extracellular matrix stops the activity of the fibroblasts. ${ }^{15}$ The last healing stage, remodeling, then begins. Remodeling can last for years and depends on the size and nature of the wound. ${ }^{15,27}$ In this phase, type 3 collagen is replaced by a stronger fiber such as type 1 collagen, but it is lined up without a specific order and is smaller than the collagen of an undamaged skin surface. ${ }^{15,27}$ This results in more strength but less elasticity. Gradually, as long as the healing process follows a physiological course of action, the scar will lose its erythematous appearance. ${ }^{15}$ The healing process undergone by the internal organs, for example, after surgery, is the same as that observed for the skin. ${ }^{26,28}$

What happens, however, if these processes have been altered? The scar can shift the healing process toward a nonphysiological state, giving origin to a hypertrophic scar (HS), a keloid scar (KS), or an atrophic scar (AS), each one with a different etiology. Scars appear after traumas, surgery, or burns. The HS is, by definition, a healing process increasing in height but always confined to the area of the original wound. ${ }^{25} \mathrm{~A} \mathrm{KS}$ not only increases in height but also proliferates beyond the borders of the original lesion. ${ }^{29} \mathrm{KSs}$ and HSs may represent two different stages of the same disease. ${ }^{30,31}$ The AS appears as a cutaneous depression. ${ }^{32}$ When the dermis and the fascia are affected by scars, these structures are altered, and their function and capacity of interaction with the external and internal environment are lacking.

Many are the reasons that provoke such events, from genetic predisposition, to age, but they are still not clearly understood. ${ }^{29,33}$ At this time, the scientific panorama offers several hypotheses, but the most endorsed is mainly the neuroinflammatory or neurogenic inflammation hypothesis.

According to some lines of thought, an excess of neuroinflammatory stimuli and a release of neuropeptides (substance $\mathrm{P}$ and peptides that release calcitonin) can be observed, which prolong the production of growth factors and cytokines, generating an extracellular matrix in excess. ${ }^{30,31}$ The neuroinflammatory overstimulation is probably a result of a reflex arc at the medullary level, which comes from the injury (sensory nerves with nonmyelinated fibers of type $\mathrm{C}$ and delta fibers) and then returns as a neuroinflammatory signal, with a consequent excess activity of neuropeptides. ${ }^{34}$ Research has confirmed an increase of nerves in the region of scarring, particularly HSs, and an accumulation of neuropeptides. ${ }^{34}$ This means a scar can present daily stimuli, enabling us to understand the symptoms we are going to examine later in this 


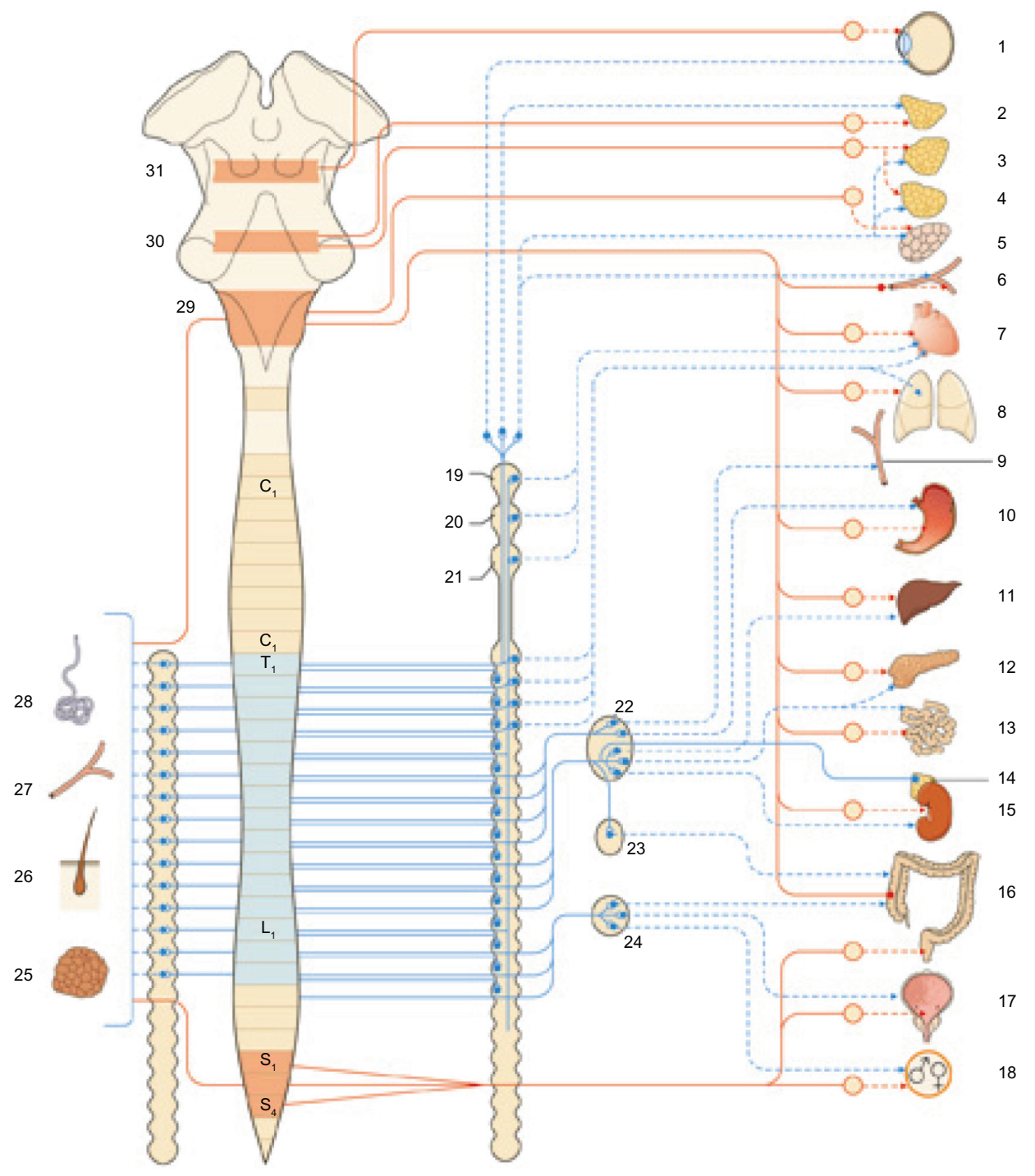

Figure 4 General organization and territories of innervation of the sympathetic nervous system (blue) and parasympathetic nervous system (red). We can logically assume that in the presence of a scar, these receptors may experience an alteration, resulting in transmitting nonphysiological signals and creating a pathological reflex arc. Reproduced with permission Anastasi et al. AA VV, Anatomia dell'uomo, 4 ed, Edi.ermes, Milano [Human Anatomy]. ${ }^{114}$

Notes: I, eye; 2, lacrimal gland; 3, submandibular gland; 4, sublingual gland; 5, parotid gland; 6, vessels; 7, heart; 8, lungs; 9, abdominal vessels; I0, stomach; II, liver; I2, pancreas; 13, small intestine; 14, adrenal gland; 15, kidney; 16, large intestine; 17, urinary bladder; 18, genital apparatus; 19, superior cervical ganglion; 20, cervical ganglion medium; 21, inferior cervical ganglion; 22, celiac ganglion; 23, superior mesenteric ganglion; 24, inferior mesenteric ganglion; 25, brown adipose tissue; 26 , hair follicles; 27 , blood vessels; 28 , sweat glands; 29 , bulb; 30, bridge; 31 midbrain.

article. What generates this inflammatory overstimulation? According to some textbooks, skin-rubbing stimulates a neurogenic inflammatory response, ${ }^{31}$ and a tight dress is enough to stimulate a neurogenic reflex arc.

According to another current thought, this neuroinflammatory response is mainly caused by stimuli of anomalous tension originated in the injury. ${ }^{31,33}$ This process provokes a release of neuropeptides from cells native to the extracellular matrix (therefore, not only those belonging to the nerve endings), stimulating an inflammatory reflex arc. $^{30,31,35}$ With reference to this idea, the tension on the injury depends on the direction of the injury itself; for example, in a vertical or horizontal direction compared with the axis of the leg. ${ }^{36}$ In fact, in the case of a horizontal scar, there will be a tension three times greater. ${ }^{37}$

Tension is certainly a factor predisposing the onset of these problems, but we still do not know whether it initiates a deviation from the physiological healing process of an injury or affects the scar once the healing process has concluded. The force lines recordable in KSs are addressed outside of the scar, with a consequent expansion of the tissue; recent studies have proven that their margins are pulled outward, with considerable peripheral tension, whereas the central area is subject to a mild tension. ${ }^{30,31}$ It is well-known that KSs and HSs frequently arise in specific sites; namely, the anterior chest, the shoulders (especially the scapular area), the lower abdomen, and the earlobes. ${ }^{36}$ 


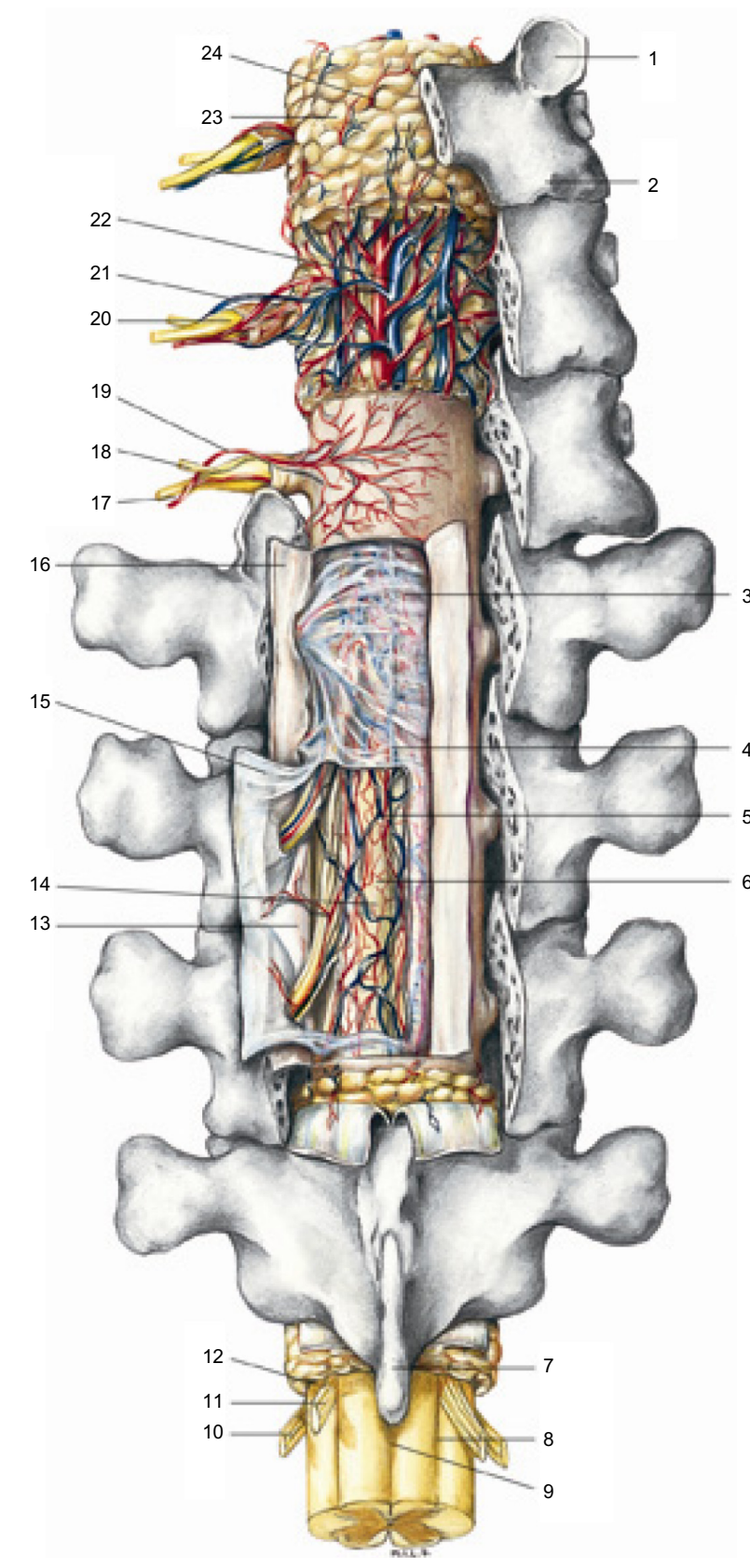

Figure $\mathbf{5}$ The structures of the spinal cord and blood vessels, rear projection, are made up of various layers but are continuous. However, it is usually ignored when the tissue where the tension is observable is in an unbalanced condition, as in the case when a scar is present, the cells cannot properly interpret the message, giving consequent anomalous responses. Reproduced with permission Anastasi et al. AA VV, Anatomia dell'uomo, 4 ed, Edi.ermes, Milano [Human Anatomy]. ${ }^{114}$

Notes: I, superior articular process; 2, inferior articular process; 3, subdural space; 4, septum posterior; 5, upper spinal vessels; 6, subarachnoid space; 7, spinous process; 8 , posterior lateral sulcus; 9 , posterior median sulcus; 10, anterior root motor; I1, sensory posterior root; 12, interradicular septum; 13, denticulate ligament; 14, spinal pia mater; 15, spinal arachnoid; 16, spinal dura mater; 17, the anterior branch of the spinal nerv; 18, posterior branch of the spinal nerve; 19, spinal vertebral artery branch; 20 , spinal ganglion; 21 , branches of the spinal vertebral vein 22 , posterior internal vertebral venous plexus; 23 , epidural fat; 24 , epidural space.

Mechanical forces may be perceived by two types of receptors: the mechanoreceptor (or mechanosensor) and the mechanosensitive nociceptor. The first deals with the information of mechanical modifications, whereas the second
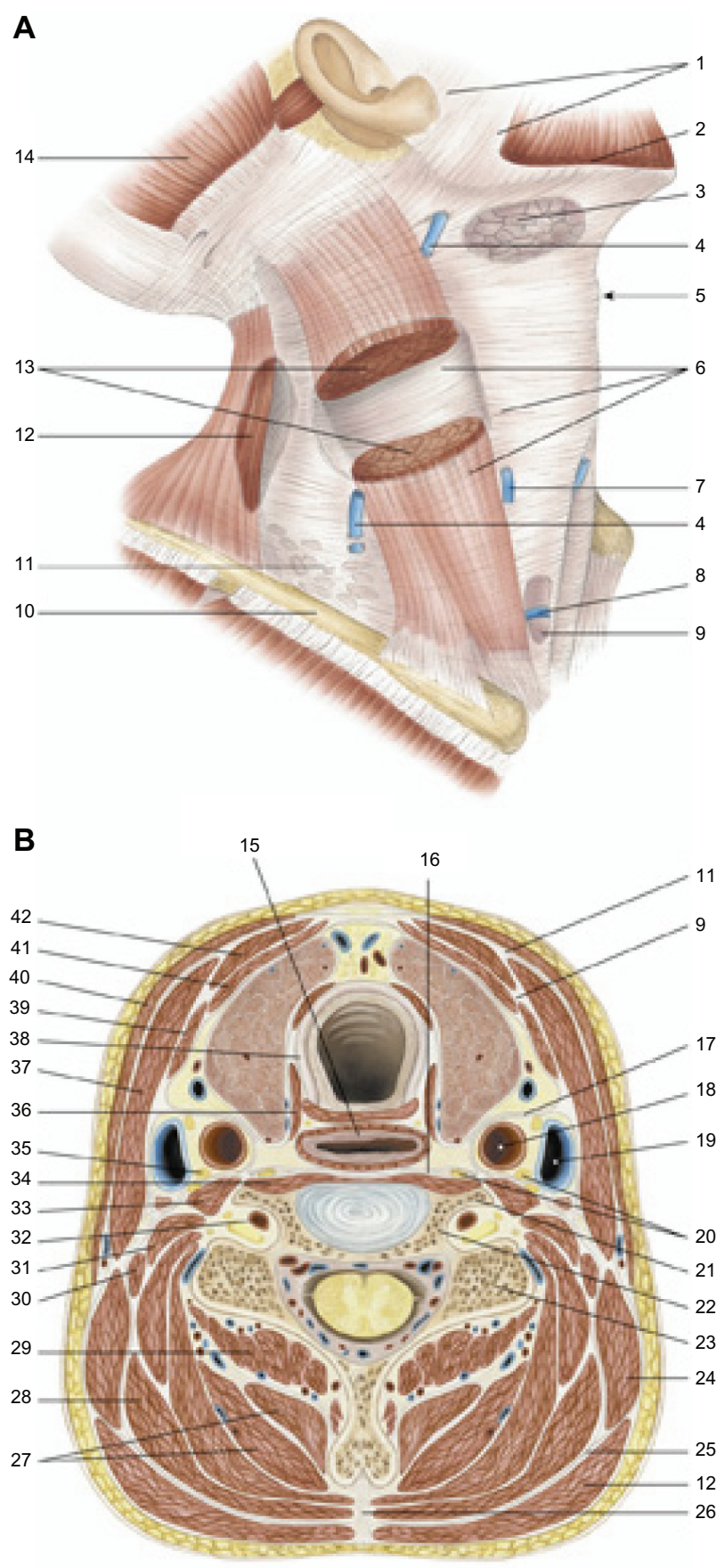

Figure 6 Fascias of the neck. Deep traumas can also affect the fascia and the viscera which then go through an identical healing process. Reproduced with permission Anastasi et al. AA VV, Anatomia dell'uomo, 4 ed, Edi.ermes, Milano [Human Anatomy]. ${ }^{114}$

Notes: I, parotid fascia, masseteric fascia; 2, platysma; 3, submandibular gland; 4, external jugular vein; 5 , laryngeal prominence; 6, superficial cervical fascia; 7 , anterior jugular vein; 8, the jugular venous arch; 9, middle cervical fascia; 10, clavicle; II, superficial cervical fascia; 12, trapezius muscle; 13, sternocleidomastoid muscle; 14, occipital muscle (of the epicranic muscle); 15, esophagus; 16, deep cervical fascia; 17, carotid sheath; 18, common carotid arter; 19, internal jugular vein; 20, chain of the sympathetic nervous system; $21,6^{\circ}$ cervical vertebrae, anterior tubercle; $22,6^{\circ}$ cervical vertebrae, transverse process; $23,6^{\circ}$ cervical vertebrae, posterior tubercle; 24 , levator scapula, 25 , nuchal's fascia; 26 , nuchal ligament; 27 , semispinalis muscle of the head and neck; 28 , splenius muscle of head and neck; 29 , multifidus muscle of the neck; 30 , posterior scalene muscle; 31 , middle scalene muscle; 32 , vertebral artery; 33 , anterior scalene muscle; 34 , long muscle of the neck; 35 , phrenic nerve; 36 , inferior constrictor muscle of the pharynx, cricopharyngeal portion; 37 , sternocleidomastoid muscle; 38 , trachea; 39 , omohyoid muscle; 40 , platysma; 4 I, muscle sternothyroidean; 42 , muscle sternohyoidean. 


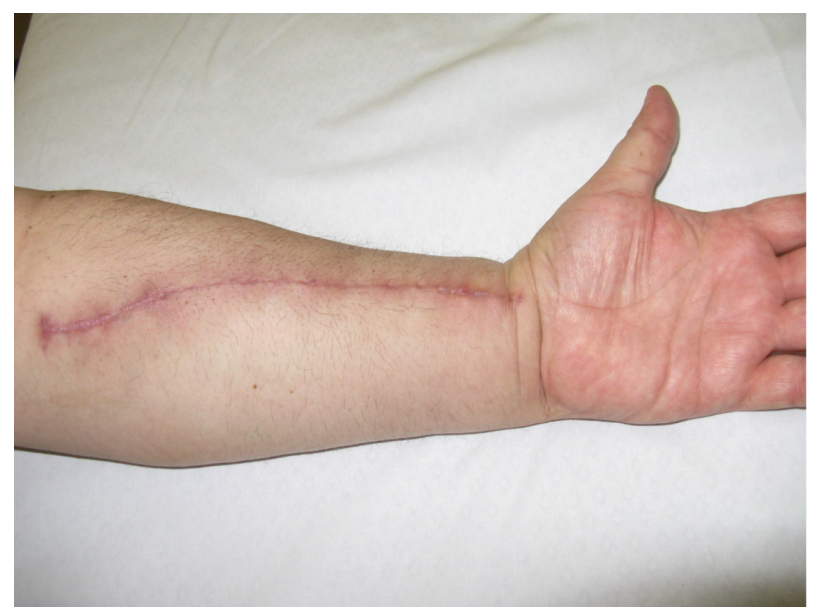

Figure $7 \mathrm{~A}$ surgery to remove the radial artery. Furthermore, the fascial tissue is made of contractile fibers, which may possibly produce spasms and consequential dysfunction and pain.

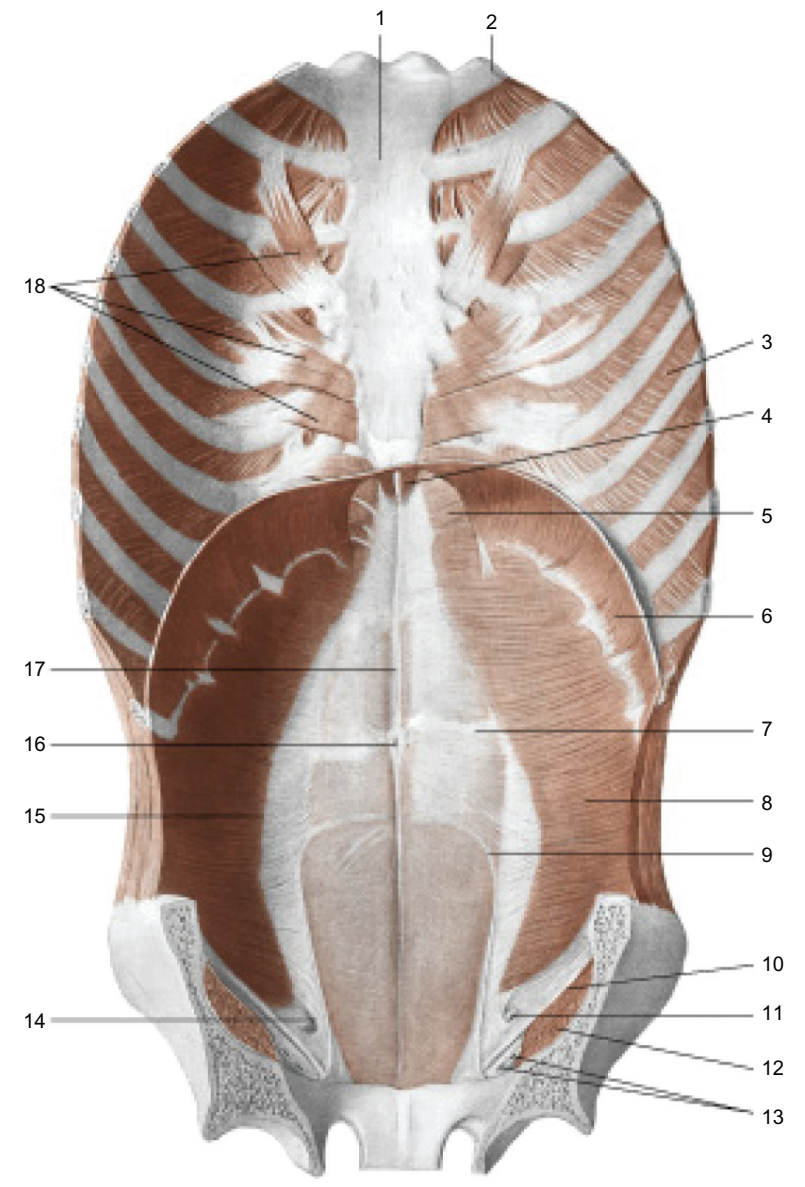

Figure 8 Continuity from the pelvis to the sternum. Muscles of the anterior wall of the trunk; view from inside. In addition, we can assume a malfunction of the respiratory diaphragm because of the stiffening of the lumbodorsal spine, to which the primary muscle of respiration is closely connected. Reproduced with permission Anastasi et al. AA VV, Anatomia dell'uomo, 4 ed, Edi.ermes, Milano [Human Anatomy]. ${ }^{114}$

Notes: I, sternum; 2, first rib; 3, internal intercostal muscle; 4, sternal part of the diaphragm; 5 , sternocostal trigon; 6 , costal part of the diaphragm; 7 , tendinous sign of the rectus abdominis muscle; 8 , transversus abdominis muscle; 9 , arcuate line; 10 , inguinal ligament; II, spermatic cord; 12, iliopsoas muscle; 13, the femoral vessels; 14, deep inguinal ring; 15, semilunar line; 16, umbilicus; 17, linea alba; 18, transverse muscle of the chest. mostly controls the information of pain. However, both convey somatic information. ${ }^{36}$ We can logically assume that in the presence of a scar, these receptors may experience an alteration, resulting in transmitting nonphysiological signals and creating a pathological reflex arc. It is worth remembering that the language of the cell is, precisely, the tension, which activates the mechanotransduction (ie, the chemicobiological and metabolic response to the tension). ${ }^{35,36,38}$ This response will be different depending on how the tension emerges and depending on different parameters. However, it is usually ignored that if the tissue where the tension is observable is in an unbalanced condition, as in the case when a scar is present, the cells cannot properly interpret the message, giving consequent anomalous responses. At this time, one of the reasons explaining the finding of KSs is the constant stretching of injured tissue. ${ }^{36,39}$ However, the real causes that give rise to a nonphysiological scar are still obscure. With regard to the lymphatic system and its correlation with nonphysiological scars, there is little information found in the medical literature. A difficulty in the lymphatic drainage of the area concerned is presumed, but it is still unknown whether this may cause further damage or not.

Deep traumas can also affect the fascia and the viscera, which then go through an identical healing process. The fascia is rich in corpuscles (ie, the Golgi's, the Pacini's, and the Ruffini's corpuscles), with proprioceptive properties and significant peripheral information, as well as with probable nociceptive function. ${ }^{40}$ Furthermore, the fascial tissue is made of contractile fibers, which may possibly produce spasms and consequential dysfunction and pain. ${ }^{40} \mathrm{Via}$ the postsynaptic dorsal column and the spinothalamic tract, the viscera send signals to the spinal cord, which convey information related to pain and to interoceptive alterations. Visceral primary afferents are known to be rich in neuropeptides, such as substance P. This information will be useful in understanding the symptomatology described later. ${ }^{41,42}$ In conclusion, we emphasize that the percentage of adhesions as a result of surgery rises to $100 \%$. An adhesion is a cicatricial event. ${ }^{43}$

\section{Connections}

One of the most important connections between the skin and the body is that with the sympathetic nervous system. Its efferent fibers stem from the preoptical center of the hypothalamus and then descend to the brainstem and the spinal cord (intermediolateral fasciculus), where they finally join other neurons. ${ }^{17,44}$ The latter are known as preganglionic neurons, whose axons laterally derive from the medulla and finally reach the sympathetic ganglions. ${ }^{17,44}$ 
The preganglionic fibers emerge from the anterior roots and, through the white rami communicantes, reach the paravertebral sympathetic chain. ${ }^{17,44}$ Sympathetic postganglionic nonmyelinated fibers depart from here (gray rami communicantes) and then come in contact with different peripheral nervous fibers, finally arriving at the various sweat glands. ${ }^{17,44}$

The sympathetic preganglionic fibers housed between the second and the ninth thoracic segment concern the skin of the superior limbs, the preganglionic fibers located between the first and the fourth thoracic segment concern the face and the eyelids, and the fibers placed between the fourth and the twelfth thoracic segment concern the entire trunk, whereas those situated between the tenth thoracic segment and the third lumbar segment concern the inferior limbs. ${ }^{17}$ The cervical tract is related to the acknowledged cervical ganglions, including the stellate ganglion of the last cervical vertebra and the first thoracic vertebra. ${ }^{17}$ Therefore, there is a metameric overlap of the sympathetic innervations.

The hypothalamic area not only transmits efferents but also receives numerous sensitive afferents; for instance, those deriving from the thermoceptive system (hot and cold receptors of the skin) and the mechanoreceptive system (receptors that participate in the proprioceptive and motor control of the skin stretch pattern), the mechanosensitive nociceptor, or again, those stemming from the trigeminal nuclei (the trigeminal system is also connected to the cerebellum), and finally, from the thalamus. ${ }^{14,17,45-47}$ The information is then integrated so as to achieve an adequate thermoregulation (ie, the hematic variation of the skin) or a better endocrine response and postural change (the cerebellum has proven to be stimulated by information from the skin) and further functions. ${ }^{17}$

The skin is connected, both in afferent and efferent mode, to the entire body and to all the systems, including emotions. Emotional sweating (also called mental sweating), which is mainly evident in the palms of the hands and feet or in the axillas, partly works independent of the sweating related to thermoregulation. ${ }^{17}$ It is controlled at different levels and depends on the central nervous system. With reference to the cortex, the anterior cingulate cortex is chiefly involved in controlling emotional sweating, whereas its dorsal half receives visual sensory information and sends, in turn, information to the brainstem to control the relationship between the eyes and the movements of the head. ${ }^{17}$ Recently, research has demonstrated that the skin performs an electrical sympathetic response, depending on the image watched and on the emotion it provokes. ${ }^{48}$

Furthermore, it is important to remember that the skin also acts in response to the stimuli of light and that melanocytes directly originate from the central nervous system from an embryological perspective. ${ }^{7,49}$

However, the electrical response of the skin varies depending on the age of the patient. In fact, in people who are older than 60 years, reactions may have a lower value, even though the information received by the skin is always conveyed through the same means of connection. ${ }^{17}$ The same variation also depends on the disease in progress. For example, people who suffer from diabetes or chronic renal failure, or people with disorders related to the central nervous system, have a reduced sympathetic response of the skin. ${ }^{17}$

Deep breathing, as well as rapid eye movement, can stimulate a sympathetic response of the skin, which is electrically recordable. ${ }^{17}$

The skin can stimulate the sympathetic nervous system, which is connected to the entire nervous system, both efferently and afferently. ${ }^{50}$

The fascia has a high density of nerve endings belonging to the sympathetic system, and according to some studies on rats, it could also have a metameric innervation, corresponding to the underlying musculature. ${ }^{21}$ However, scientific literature still offers little material on the innervation of the fascia.

The electrical activity of the nervous system is not restricted to the mere distribution of electrical efferent impulses toward a sole direction; in fact, nerves convey not only electrical impulses but also chemicobiological, neurotrophic, and at the same time, immune substances ${ }^{40}$ This process, which is not simply an electrical activity, can take place both in afferent and efferent mode, regardless of the nerve's function. ${ }^{40}$ For instance, depending on the nature of the muscular contraction, the contractile tissue synthesizes some neurotrophic molecules (such as neurotrophin 3, neurotrophin 4, brain-derived neurotrophic factor, and so on), which can move along the axis cylinder in retrograde motion until reaching the motoneuron structure to modify its form and, as a result, its function. ${ }^{40}$ Therefore, a section of skin affected by a scar transmits, via the sympathetic nervous system, chemicobiological and metabolic information to the medullary neurons and interneurons of the related metameric level; this affects other motoneurons or sensitive neurons at the same level, whether ipsilaterally or controlaterally. ${ }^{40}$ The transmission of an electrical impulse to a specific point is easier than the conveyance of a metabolic message to a single neuron. That is why there can be a general symptomatology that is different from the single symptoms observed in a restricted area. ${ }^{40}$

When there is a fascial injury, there is a fascial dysfunction. ${ }^{21,40}$ A physiological alteration in any part of the body will affect, as a result, everything that is covered 
by the connective sheet: the symptom will arise in the area concerned with the alteration or, in contrast, in a distal area, when this is not capable of adapting to the new stressor. ${ }^{40}$

With reference to the symptoms, what happens in the presence of a scar? We present here some clinical case-studies taken from the existing scientific literature and from our professional experience.

\section{Symptoms and clinical scenarios: the ankle}

A surgical operation or a burn can reduce the range of movement of an ankle or cause other problems to the patient as a result of the adhesions that, regardless of the surgical procedure adopted, are traceable in the underlying layers (from the skin to the bone, from the fascia to the nervous tissue).$^{51-54}$ The information coming from the cicatricial area does not just originate from the skin but from all the tissues affected by the trauma. When the patient walks, not only will the ankle not work according to a physiological motor pattern but the afferents sent to the central nervous system will be altered. ${ }^{9,55}$ The same alteration will be observed in the efferents when they return to the ankle and to the whole motor system, as a consequence disturbing postural adjustments and posture in general. ${ }^{18,19}$ In the course of the variety of information, the symptom will arise in the area less capable of compliance. ${ }^{40}$ For example, symptoms will be reported when touching an area of the spinal musculature that is more tonic and that coincides with the metameric innervation. ${ }^{44}$ When stimulated in this way, the sympathetic nervous system can produce a local vasoconstriction of the ankle, again disturbing the postural balance. ${ }^{56,57}$ Frequently, the patient experiences pain, even in the case of a small or aesthetically acceptable scar, because the adhesions trap the nerve (the peroneal nerve). ${ }^{52,53,58}$ As a result of the constant stimulation of pain, the central and peripheral nervous systems adapt themselves and change their structure (allodynia and hyperalgesia), creating a vicious circle..$^{59,60}$ The same events occur in the lesions of the syndesmotic joints and the interosseous membranes. The mechanism of injuries to the tibiofibular syndesmosis includes isolated rupture and rupture in combination with fractures of the ankle. Current hypotheses of surgical treatment include fixation, by applying bioabsorbable screws, syndesmotic stapling, and syndesmotic hooks, and the widely used screw fixation. ${ }^{61}$ Scars and adhesions at this level will alter the dynamics of the gait and the correct distribution of loads. ${ }^{9,62,63}$ We can hypothesize the presence of a vertebral dysfunction at the metameric level, which results in a painful symptomatology, because of an abnormal increase in the muscular tone and in loads incorrectly distributed, with consequent postural alteration. Again, this dysfunction is attributable to a sympathetic return efferent, influenced by electrical and biochemical afferents. ${ }^{64,65}$ In addition, we can assume a malfunction of the respiratory diaphragm because of the stiffening of the lumbodorsal spine, to which the primary muscle of respiration is closely connected. ${ }^{40} \mathrm{~A}$ scar located on the ankle may also be responsible for back pain for another reason: The entrapment of a nerve, for example, the peroneal nerve arising from the sciatic nerve, which cannot glide through the tissues, pulls out the root of the sciatic nerve. ${ }^{66,67}$ This will cause irritation, inflammation, and pain. ${ }^{66}$

Consideration should be given to the fascial system of the lower limbs, communicating with the whole body, and in particular with the thoracolumbar fascia. ${ }^{68}$ The gluteal fascia departs from the iliac crest and, through the sacrum and the coccygeal bone, runs to the femoral fascia; the latter will then become the tibial fascia, involving the tibia and fibula, finally enclosing the whole foot. ${ }^{69-72}$ The gluteus maximus is part of the thoracolumbar fascia, and the fascia of the lower limbs is its logical extension. ${ }^{40}$ We can then assume that if a scar on the ankle creates an adhesion, this unusual tension will also be recorded by the thoracolumbar fascia, with the consequent appearance of back pain or dysfunctions in the shoulders. It is acknowledged that the thoracolumbar fascia can cause lower back pain or anomalies in the arthrokinematics of the shoulders. ${ }^{21}$ Furthermore, when the fascial surface is not in its normal physiological condition, the normal fascial receptors can develop into nociceptors, with a more complex symptomatology. ${ }^{68,71}$

The sympathetic nervous system is connected to the emotions, and we can assume an emotional alteration resulting from nonphysiological information arising from the periphery. ${ }^{48}$ We can still hypothesize the presence of thalamic and hypothalamic dysfunctions because of relations with the sympathetic system and skin. ${ }^{17,44}$

We can also logically theorize that in time, a scar on the ankle might generate a visceral dysfunction. The splanchnic nerves pass through the diaphragm and constitute the celiac ganglion (which originates in T4-T5-T9), the superior mesenteric plexus (which derives from T10-T11-T12), and the inferior mesenteric plexus (related to L1-L2). ${ }^{40}$ Hence, because of a metameric relationship, in the case of chronic colitis, we may encounter some problems at the level of the superior mesenteric plexus or the inferior mesenteric plexus despite the absence of pain in the ankle itself. Continuing with other clinical hypotheses, we could find a patient whose trigeminal system has been involved in a case of 
cicatricial stimulation. The visceral afferents are connected to Lissauer's tract (namely, the dorsolateral fasciculus or tract), which belongs to the trigeminal system. ${ }^{40}$ Furthermore, the trigeminal system sends afferents to the hypothalamic preoptic region, creating a vicious cycle of pathological patterns. ${ }^{17}$ The trigeminal system is connected to the entire medullary system; for instance, by means of the medial longitudinal fasciculus. ${ }^{40}$ This is a composition of fibers that connect the mesencephalon and most cranial nerves, such as the trigeminal nerve $(\mathrm{V})$, and the cranial nerves that innervate the eye (II, III, IV, the first branch of cranial nerve V, and VI), the tongue (the hypoglossal nerve, XII), and the cervical base (C1-C3). ${ }^{40}$ Therefore, the medial longitudinal fasciculus is an important path of connection whose margins go from the mesencephalon-diencephalon to the lumbar spinal cord (L4) and further, at least according to some sources. ${ }^{40}$ This pathway is essential to understanding the relationship between sight and posture. A cicatricial problem could send pathological information to the medulla, affecting the whole body system and expanding the symptomatology.

A symptom does not necessarily arise where the problem begins, but it can occur in distant sites because the body is a sole entity. ${ }^{73}$

\section{Symptoms and clinical scenarios: lumbar surgery}

Let us now consider other examples. Surgery in the case of a herniated disk can produce many symptoms, whether local or distant from the scar, regardless of the surgical procedure adopted. ${ }^{74,75}$ The periradicular and epidural scar resulting from surgery prevents the nerve from sliding properly during the movement of the lower limbs; this, along with a decreased vascular supply recorded during the mechanical action, produces pain. ${ }^{76,77}$ We already know that when the dura mater exits from the skull, it contacts C2 before arriving at S2. ${ }^{40,78}$ We can logically presume the existence of a tension along the path of the dura mater because of an epidural scar, with symptoms that affect the nerve roots even if they are distant from the site of surgery. Furthermore, some anatomical structures are directly related to the dura mater, such as the nuchal ligament (innervated by $\mathrm{C} 2$ ) and the rectus capitis posterior minor (innervated by $\mathrm{C} 1$ ). ${ }^{40,79}$ The former is part of the thoracolumbar fascia, and the latter is part of the deep cervical fascia. ${ }^{40}$

A branch of C2 innervates the lower area of the tentorium cerebelli. In this dermatomeric area, we find the spinal trigeminal ganglion and the transverse cervical nerve. ${ }^{40}$ We can assume that a lumbar scar can produce symptoms of functional impairment in the shoulders or provoke trigeminal facial pain and temporomandibular joint pain, as well as cervical problems. Surgery in the lumbar area will necessarily involve the integrity of the thoracolumbar fascia. It develops posteriorly from the sacral region and, through the thoracic region, finally reaches the cervical region. ${ }^{40}$ It involves muscles such as the latissimus dorsi, the trapezius, the serratus posterior inferior, the gluteus maximus, and the external oblique, as well as the ligaments that connect the ileum to the sacrum; this fascial system separates the paraspinal muscle from the muscles of the posterior abdominal wall. ${ }^{21,80}$ The thoracolumbar fascia is essential for the muscles that involve the spinal column, posture, transfer of loads, and respiration. ${ }^{21}$ It is joined to the bicep femoris and the semimembranosus and semitendinosus muscles, in regard to the lower limbs, and represents the fascial continuation of the upper limbs precisely of the pectoral fascia (which is connected to the deltoid and brachial fascia and to the rectus abdominis fascia). ${ }^{21,81}$ The thoracolumbar fascia envelops the body posteriorly, continuing with other fascial structures up to the pubis. ${ }^{81}$ Therefore, we can hypothesize a very wide scenario of symptoms, which can arise even far from the initial scar. The cluneal nerves arise from the first three lumbar vertebrae and the first three sacral roots, running through the surface of the muscular portion of the latissimus dorsi and gluteus maximus near the iliac crest. ${ }^{82}$ Lower back pain or pelvic and perineal pain can be experienced in cases of tensional dysfunction related to the thoracolumbar fascia or because of the entrapment of the roots of the previously mentioned nerves. ${ }^{82-84}$ The serratus posterior inferior is covered by the latissimus dorsi, the trapezius, and the rhomboid muscles, and it acts in synergy with the quadratus lumborum. ${ }^{85}$ According to some authors, its main function is to act as a proprioceptor muscle, in this way giving important information for correct spinal movement and breathing. ${ }^{85}$ In connection with a scar involving the thoracolumbar fascia, we can also speculate an alteration of posture and of the distribution of the load during walking, in addition to some problems at the shoulders resulting from an altered tensional status of the serratus posterior muscle. ${ }^{86}$ The same thoracolumbar fascia, in the presence of abnormal tensions, can convey information of pain to the spinal cord neurons, with consequent lower back pain. ${ }^{87}$ When the pressure of the intervertebral disk is altered, the deepest muscles alter their contractile activation, increasing the possibility of spinal pain. ${ }^{88}$ This event can be attributed to surgery or to the distribution of altered fascial loads, and again to different information coming from the skin itself. ${ }^{86,89}$ Finally, consideration should be given to the fact that the muscles of the pelvis are in a condition of preactivation and 
are more tonic if compared with other muscles at rest, which means that a further tensional change in the thoracolumbar fascia will give symptoms related to posture, walking, and visceral functionality of the pelvic area ${ }^{80} \mathrm{~A}$ lumbar scar could increase the tension of the deep fascia of the neck, pulling the stellate ganglion (which is located above the first rib and derives from the unification of the inferior cervical ganglion and the first thoracic ganglion of the sympathetic system). This event may cause symptoms at the level of the cervical and thoracic outlet and negatively affect all the neural structures related to it. ${ }^{40,90,91}$ To exclusively treat the joint negatively involved will not solve the problem.

\section{Symptoms and clinical scenarios: the elbow}

In the case of an altered mechanical stimulation, the fascia might be constricted, with a consequent increase of its basic tone, creating in this way a pathological vicious cycle. ${ }^{21,23,92}$ The fascia is the largest mechanosensitive organ, and with its muscle, skin, and periosteal connections, it can cause symptoms possibly far from the source of the problem. ${ }^{71}$ In addition, the fascia, as any other tissue including the skin does, keeps in itself the memory of the trauma, which means a symptom may occur without any apparent cause of direct stimulation. ${ }^{93}$ When there is a scar resulting from traumas or surgery in the elbow, the brachial fascia is involved, with adhesions of different subcutaneous layers. ${ }^{68}$ Repetitive mechanical stress on a scar may result in an excessive collagen deposition, which enhances fibrosis. ${ }^{94}$ Symptoms can arise later as the result of a scar. ${ }^{66}$ The radial and ulnar nerves also may be trapped, thus causing pain.

According to our clinical experience, there is often rigidity in the vertebral body corresponding to the output of the nerves. ${ }^{58}$ The arcade of Struthers, the Frohse's arcade, and the sublime bridge are connective structures that correlate the brachial fascia anteriorly and posteriorly at the level of the elbow. ${ }^{95-97}$ The brachial fascia arrives at the deltoid fascia, which derives from the pectoral fascia. ${ }^{81,98,99}$ The pectoral fascia, in its upper portion, is the continuation of the deep fascia of the neck, whereas in its lower portion, it is connected through the sternum to the abdominal fascia and the pubis; posteriorly, it is connected to the trapezius and the latissimus dorsi, and thus to the thoracolumbar fascia. ${ }^{81,100} \mathrm{~A}$ scar on the elbow may cause postural problems, which affect walking, and back and neck pain. ${ }^{66,81,100} \mathrm{~A}$ fascial dysfunction that starts at the elbow can affect the pectoral fascia at the level of the clavicle and the subclavian muscle. ${ }^{68}$ It can be assumed that the stellate ganglion and the ulnar nerve are negatively affected by this tension, developing the thoracic outlet syndrome. Overstimulation of the stellate ganglion, and thus of the sympathetic system, could alter the trigeminal function, particularly affecting the vasomotor control of the face. ${ }^{45}$

\section{Symptoms and clinical scenarios: abdominal surgery}

Finally, we analyze the problems that can arise from abdominal visceral surgery. Communication between the viscera and the brain is continuous. The brain receives (and responds to) continuous dynamic feedback of afferent visceral signals through neural and humoral pathways. ${ }^{42}$ Spinal visceral afferents project themselves toward the dorsal horns of the spinal cord, into the spinothalamic tract; humoral information is processed through circumventricular organs and within other brain regions, including the hypothalamus. ${ }^{42}$ The visceral efferents, especially those of the sympathetic system, are the solar ganglia, the superior mesenteric ganglion and the lower one, and the sacral ganglion. ${ }^{40}$

The incidence of detection of adhesions after visceral surgery may rise to $100 \%$, depending on the texts examined. ${ }^{43,101,102}$ Necessarily, we identify symptoms resulting from the scar, such as meteorism, irregular bowel movements, chronic abdominal pain, digestive disorders, and intestinal obstruction. ${ }^{43}$ Abdominal fascial connections with the sternum and the pubis will determine postural problems, back pain, and dysfunctions in walking.

The distal rectus abdominis sheath has a direct connection with the gracilis and adductor longus muscles through fascial connections; this relationship is important to distribute the load of the step between the trunk and the lower limbs. ${ }^{103}$ Over time, an alteration of the loads may lead to pubalgy, and even to back pain. The scar resulting from a cesarean section may lead to infertility, menorrhalgia, lower abdominal pain, dyspareunia and dysmenorrhea, endometriosis, and pelvic pain. ${ }^{104-106} \mathrm{~A}$ pelvis that is not physiologically mobile will result in dysfunctions of the respiratory diaphragm, the thoracic outlet, the mouth floor, and the reciprocal tensional membrane. ${ }^{40}$ Therefore, a visceral problem can alter the structure.

It is worth remembering that there is a convergence of viscerosomatic information in the spinal cord. ${ }^{107,108}$ An abdominal scar may draw the inferior mesenteric plexus, bringing about symptoms related to the sympathetic nervous system and to the correlated visceral and somatic spheres (T11-L2), as studies on cadavers have already proven. ${ }^{109}$ Therefore, visceral adhesions can affect the sympathetic ner- 
vous system, with varied symptomatology such as vertebral stiffness corresponding to the metameric innervation. ${ }^{110}$ The spinal trigeminal nucleus receives visceral information via the vagus nerve (and the glossopharyngeal nerve). This may lead to a malfunction with symptoms related to the trigeminal system, from a toothache to a headache, and from painful chewing to optical problems. ${ }^{111}$

The general rule is to check scars, even when they seem to be normal. Research has already proven that even if a scar appears to be hypotonic to the touch, its electrical activity is higher in a patient who has been ordered to move actively than the electrical activity recorded, in the presence of undamaged skin, in the same person performing the same movements. ${ }^{112}$ This applies to every part of the body.

To conclude, we underline that the fascias envelop the viscera and that the fascia would seem capable of conducting electrical activity under mechanical stimuli, giving rise to additional symptoms. ${ }^{113}$

\section{Conclusion}

The skin is an organ that can influence body homeostasis. It is good practice, when evaluating the clinical picture of a patient, to always ascertain the presence of scars. Looking at the patient as a system and not just as a symptom or a symptomatological segment will help the clinician, and all those professionals who use manual techniques, to find a more effective treatment. A scar can produce different symptoms, which can affect the neurological sphere, the fascial, and the visceral area. The skin surface is a means to communicate with the nervous system, to understand it, and to give therapeutic information. We can conclude by affirming that the skin and the fascias represent the skeletal system of the nervous system.

\section{Acknowledgments}

We want to thank our families, who have always been supportive and patient with us. We also want to thank the friends of Advanced Osteopathy Institute.

\section{Disclosure}

The authors report no conflicts of interest in this work.

\section{References}

1. Fuchs E, Horsley V. More than one way to skin ... Genes Dev. 2008;22(8):976-985.

2. Benitah SA, Frye M. Stem cells in ectodermal development. J Mol Med (Berl). 2012;90(7):783-790.

3. Macias H, Hinck L. Mammary gland development. Wiley Interdiscip Rev Dev Biol. 2012;1(4):533-557.

4. Miletich I, Sharpe PT. Neural crest contribution to mammalian tooth formation. Birth Defects Res C Embryo Today. 2004;72(2):200-212.
5. Monahan P, Himes AD, Parfieniuk A, Raetzman LT. p21, an important mediator of quiescence during pituitary tumor formation, is dispensable for normal pituitary development during embryogenesis. Mech Dev. 2012;128(11-12):640-652.

6. Tapadia MD, Cordero DR, Helms JA. It's all in your head: new insights into craniofacial development and deformation. J Anat. 2005;207(5): 461-477.

7. Adameyko I, Lallemend F, Aquino JB, et al. Schwann cell precursors from nerve innervation are a cellular origin of melanocytes in skin. Cell. 2009;139(2):366-379.

8. Sidgwick GP, Bayat A. Extracellular matrix molecules implicated in hypertrophic and keloid scarring. J Eur Acad Dermatol Venereol. 2012;26(2):141-152.

9. Rowe MJ, Tracey DJ, Mahns DA, Sahai V, Ivanusic JJ. Mechanosensory perception: are there contributions from bone-associated receptors? Clin Exp Pharmacol Physiol. 2005;32(1-2):100-108.

10. Brend T, Holley SA. Balancing segmentation and laterality during vertebrate development. Semin Cell Dev Biol. 2009;20(4):472-478.

11. Kardon G. Development of the musculoskeletal system: meeting the neighbors. Development. 2011;138(14):2855-2859.

12. Slukvin II. Deciphering the hierarchy of angiohematopoietic progenitors from human pluripotent stem cells. Cell Cycle. 2013;12(5):720-727.

13. Di Meglio P, Perera GK, Nestle FO. The multitasking organ: recent insights into skin immune function. Immunity. 2011;35(6):857-869.

14. O'Brien GS, Rieger S, Wang F, et al. Coordinate development of skin cells and cutaneous sensory axons in zebrafish. J Comp Neurol. 2012;520(4):816-831.

15. Bran GM, Goessler UR, Hormann K, Riedel F, Sadick H. Keloids: current concepts of pathogenesis (review). Int J Mol Med. 2009;24(3): 283-293.

16. Jang SH, Seo JP, Ahn SH, Lee MY. Comparison of cortical activation patterns by somatosensory stimulation on the palm and dorsum of the hand. Somatosens Mot Res. 2013;30(3):109-113.

17. Vetrugno R, Liguori R, Cortelli P, Montagna P. Sympathetic skin response: basic mechanisms and clinical applications. Clin Auton Res. 2003;13(4):256-270.

18. Mouchnino L, Blouin J. When standing on a moving support, cutaneous inputs provide sufficient information to plan the anticipatory postural adjustments for gait initiation. PLoS One. 2013;8(2):e55081.

19. Macefield VG. Physiological characteristics of low-threshold mechanoreceptors in joints, muscle and skin in human subjects. Clin Exp Pharmacol Physiol. 2005;32(1-2):135-144.

20. Han J, Lee JE, Jin J, et al. The spatiotemporal development of adipose tissue. Development. 2011;138(22):5027-5037.

21. Willard FH, Vleeming A, Schuenke MD, Danneels L, Schleip R. The thoracolumbar fascia: anatomy, function and clinical considerations. J Anat. 2012;221(6):507-536.

22. van der Wal J. The architecture of the connective tissue in the musculoskeletal system-an often overlooked functional parameter as to proprioception in the locomotor apparatus. Int J Ther Massage Bodywork. 2009;2(4):9-23.

23. Chaudhry H, Schleip R, Ji Z, Bukiet B, Maney M, Findley T. Three-dimensional mathematical model for deformation of human fasciae in manual therapy. J Am Osteopath Assoc. 2008;108(8):3793-3790.

24. Grinnell F. Fibroblast mechanics in three-dimensional collagen matrices. J Bodyw Mov Ther. 2008;12(3):191-193.

25. Zhu Z, Ding J, Shankowsky HA, Tredget EE. The molecular mechanism of hypertrophic scar. J Cell Commun Signal. Epub March 18, 2013.

26. Sarrazy V, Billet F, Micallef L, Coulomb B, Desmoulière A. Mechanisms of pathological scarring: role of myofibroblasts and current developments. Wound Repair Regen. 2011;19 Suppl 1:s10-S15.

27. Profyris C, Tziotzios C, Do Vale I. Cutaneous scarring: Pathophysiology, molecular mechanisms, and scar reduction therapeutics Part I. The molecular basis of scar formation. J Am Acad Dermatol. 2012;66(1): 1-10.

28. Bond JE, Ho TQ, Selim MA, Hunter CL, Bowers EV, Levinson H. Temporal spatial expression and function of non-muscle myosin II isoforms IIA and IIB in scar remodeling. Lab Invest. 2011;91(4):499-508. 
29. Carantino I, Florescu IP, Carantino A. Overview about the keloid scars and the elaboration of a non-invasive, unconventional treatment. $J$ Med Life. 2010;3(2):122-127.

30. Ogawa R. Mechanobiology of scarring. Wound Repair Regen. 2011; 19 Suppl 1:s2-s9.

31. Akaishi S, Ogawa R, Hyakusoku H. Keloid and hypertrophic scar: neurogenic inflammation hypotheses. Med Hypotheses. 2007;1(1): 32-38.

32. Weiss ET, Chapas A, Brightman L, et al. Successful treatment of atrophic postoperative and traumatic scarring with carbon dioxide ablative fractional resurfacing: quantitative volumetric scar improvement. Arch Dermatol. 2010;146(2):133-140.

33. Wolfram D, Tzankov A, Pülzl P, Piza-Katzer H. Hypertrophic scars and keloids - a review of their pathophysiology, risk factors, and therapeutic management. Dermatol Surg. 2009;35(2):171-181.

34. Scott JR, Muangman P, Gibran NS. Making sense of hypertrophic scar: a role for nerves. Wound Repair Regen. 2007;15 Supp1 1:S27-S31.

35. Chin MS, Lancerotto L, Helm DL, et al. Analysis of neuropeptides in stretched skin. Plast Reconstr Surg. 2009;124(1):102-113.

36. Ogawa R. Keloid and hypertrophic scarring may result from a mechanoreceptor or mechanosensitive nociceptor disorder. Med Hypotheses. 2008;71(4):493-500.

37. Miyamoto J, Nagasao T, Miyamoto S, Nakajima T. Biomechanical analysis of stresses occurring in vertical and transverse scars on the lower leg. Plast Reconstr Surg. 2009;124(6):1974-1979.

38. Huang C, Ogawa R. Roles of lipid metabolism in keloid development. Lipids Health Dis. 20131;12:60.

39. Park TH, Seo SW, Kim JK, Chang CH. Management of chest keloids. J Cardiothorac Surg. 2011;6:49.

40. Bordoni B, Zanier E. Anatomic connections of the diaphragm: influence of respiration on the body system. J Multidiscip Healthc. 2013;6: 281-291.

41. Wang Y, Wu J, Lin Q, Nauta H, Yue Y, Fang L. Effects of general anesthetics on visceral pain transmission in the spinal cord. Mol Pain. 2008;4:50.

42. Critchley HD, Harrison NA. Visceral influences on brain and behavior. Neuron. 2013;77(4):624-638.

43. Brüggmann D, Tchartchian G, Wallwiener M, Münstedt K, Tinneberg HR, Hackethal A. Intra-abdominal adhesions: definition, origin, significance in surgical practice, and treatment options. Dtsch Arztebl Int. 2010;107(44):769-775.

44. Longmire DR. An electrophysiological approach to the evaluation of regional sympathetic dysfunction: a proposed classification. Pain Physician. 2006;9(1):69-82.

45. Nolano M, Provitera V, Caporaso G, et al. Cutaneous innervation of the human face as assessed by skin biopsy. J Anat. 2013;222(2): $161-169$.

46. Hall SC, Fazalbhoy A, Birznieks I, Macefield VG. Biphasic effects of tonic stimulation of muscle nociceptors on skin sympathetic nerve activity in human subjects. Exp Brain Res. 2012;221(1):107-114.

47. Upadhyay J, Knudsen J, Anderson J, Becerra L, Borsook D. Noninvasive mapping of human trigeminal brainstem pathways. Magn Reson Med. 2008;60(5):1037-1046.

48. Henderson LA, Stathis A, James C, Brown R, McDonald S, MacefieldVG. Real-time imaging of cortical areas involved in the generation of increases in skin sympathetic nerve activity when viewing emotionally charged images. Neuroimage. 2012;62(1):30-40.

49. Adameyko I, Lallemend F. Glial versus melanocyte cell fate choice: Schwann cell precursors as a cellular origin of melanocytes. Cell Mol Life Sci. 2010;67(18):3037-3055.

50. Mondelli M, Aretini A, Ballerini M, Vecchiarelli B, Rossi A. Sympathetic skin response. Glabella stimulation may be more useful than peripheral nerve stimulation in clinical practice. Auton Neurosci. 2011;164(1-2):101-104.

51. Grishkevich VM. Ankle dorsiflexion postburn scar contractures: anatomy and reconstructive techniques. Burns. 2012;38(6): 882-888.
52. Lui TH. Extensor tendons and deep peroneal nerve adhesion: Treated by complete anterior ankle arthroscopic capsulotomy. Foot Ankle Surg. 2012;18(1):e1-e3.

53. Kim BS, Choi WJ, Kim J, Lee JW. Residual pain due to soft-tissue impingement after uncomplicated total ankle replacement. Bone Joint J. 2013;95-B(3):378-383.

54. Melham TJ, Sevier TL, Malnofski MJ, Wilson JK, Helfst RH Jr. Chronic ankle pain and fibrosis successfully treated with a new noninvasive augmented soft tissue mobilization technique (ASTM): a case report. Med Sci Sports Exerc. 1998;30(6):801-804.

55. Gervasio S, Farina D, Sinkjær T, Mrachacz-Kersting N. Crossed reflex reversal during human locomotion. J Neurophysiol. 2013;109(9): 2335-2344.

56. Gilbey MP. Sympathetic rhythms and nervous integration. Clin Exp Pharmacol Physiol. 2007;34(4):356-361.

57. Raju S, Sanford P, Herman S, Olivier J. Postural and ambulatory changes in regional flow and skin perfusion. Eur JVasc Endovasc Surg. 2012;43(5):567-572.

58. Elliot D, Lloyd M, Hazari A, Sauerland S, Anand P. Relief of the pain of neuromas-in-continuity and scarred median and ulnar nerves in the distal forearm and wrist by neurolysis, wrapping in vascularized forearm fascial flaps and adjunctive procedures. J Hand Surg Eur Vol. 2010;35(7):575-582.

59. Zwerver J, Konopka KH, Keizer D, Dekker R, van Wilgen CP. Does sensitisation play a role in the pain of patients with chronic patellar tendinopathy? Br J Sports Med. 2013;47(9):e2.

60. Day JA, Copetti L, Rucli G. From clinical experience to a model for the human fascial system. J Bodyw Mov Ther. 2012;16(3):372-380.

61. Stein G, Eichler C, Ettmann L, et al. Tibiofibular screw fixation for syndesmotic ruptures: a biomechanical analysis. Surg Radiol Anat. 2012;34(7):593-597.

62. Skraba JS, Greenwald AS. The role of the interosseous membrane on tibiofibular weightbearing. Foot Ankle. 1984;4(6):301-304.

63. Harrison JW, Siddique I, Powell ES, Shaaban H, Stanley JK. Does the orientation of the distal radioulnar joint influence the force in the joint and the tension in the interosseous membrane? Clin Biomech (Bristol, Avon). 2005;20(1):57-62.

64. Brumagne S, Janssens L, Knapen S, Claeys K, Suuden-Johanson E. Persons with recurrent low back pain exhibit a rigid postural control strategy. Eur Spine J. 2008;17(9):1177-1184.

65. Shirzadi A, Drazin D, Jeswani S, Lovely L, Liu J. Atypical presentation of thoracic disc herniation: case series and review of the literature. Case Rep Orthop. 2013:621476.

66. Leijnse JN, Rietveld AB. Left shoulder pain in a violinist, related to extensor tendon adhesions in a small scar on the back of the wrist. Clin Rheumatol. 2013;32(4):501-506.

67. Drake RL, Vogl AW, Mitchell AWM. Gray's Anatomy for Students. 2nd ed. London: Elsevier-Churchill-Livingstone; 2009.

68. Stecco A, Macchi V, Stecco C, et al. Anatomical study of myofascial continuity in the anterior region of the upper limb. J Bodyw Mov Ther. 2009;13(1):53-62.

69. Paoletti S. The Fasciae: Anatomy, Dysfunction and Treatment. Seattle: Eastland Press; 2006

70. Stecco C, Pavan PG, Porzionato A, et al. Mechanics of crural fascia: from anatomy to constitutive modelling. Surg Radiol Anat. 2009;31(7): 523-529.

71. Benjamin M. The fascia of the limbs and back - a review. J Anat. 2009;214(1):1-18.

72. Abu-Hijleh MF, Harris PF. Deep fascia on the dorsum of the ankle and foot: extensor retinacula revisited. Clin Anat. 2007;20(2): 186-195.

73. Bordoni B, Zanier E. Cranial nerves XIII and XIV: nerves in the shadows. J Multidiscip Healthc. 2013;6:87-91.

74. Kim CH, Chung CK, Jahng TA, Yang HJ, Son YJ. Surgical outcome of percutaneous endoscopic interlaminar lumbar diskectomy for recurrent disk herniation after open diskectomy. J Spinal Disord Tech. 2012;25(5):E125-E133. 
75. Fransen P. Prevention of scar tissue formation in spinal surgery: state of the art and review of the literature. J Neurosurg Sci. 2011;55(3): 277-281.

76. Kobayashi S, Takeno K, Yayama T, et al. Pathomechanisms of sciatica in lumbar disc herniation: effect of periradicular adhesive tissue on electrophysiological values by an intraoperative straight leg raising test. Spine (Phila Pa 1976). 2010;35(22):2004-2014.

77. Rönnberg K, Lind B, Zoega B, et al. Peridural scar and its relation to clinical outcome: a randomised study on surgically treated lumbar disc herniation patients. Eur Spine J. 2008;17(12):1714-1720.

78. Goodman BS, Bayazitoglu M, Mallempati S, Noble BR, Geffen JF. Dural puncture and subdural injection: a complication of lumbar transforaminal epidural injections. Pain Physician. 2007;10(5): 697-705.

79. Andary MT, Hallgren RC, Greenman PE, Rechtien JJ. Neurogenic atrophy of suboccipital muscles after a cervical injury: a case study. Am J Phys Med Rehabil. 1998;77(6):545-549.

80. Carvalhais VO, Ocarino Jde M, Araújo VL, Souza TR, Silva PL, Fonseca ST. Myofascial force transmission between the latissimus dorsi and gluteus maximus muscles: an in vivo experiment. J Biomech. 2013;46(5):1003-1007.

81. Stecco A, Masiero S, Macchi V, Stecco C, Porzionato A, De Caro R. The pectoral fascia: anatomical and histological study. J Bodyw Mov Ther. 2009;13(3):255-261.

82. Tubbs RS, Levin MR, Loukas M, Potts EA, Cohen-Gadol AA. Anatomy and landmarks for the superior and middle cluneal nerves: application to posterior iliac crest harvest and entrapment syndromes. J Neurosurg Spine. 2010;13(3):356-359.

83. Kuniya H, Aota Y, Saito T, et al. Anatomical study of superior cluneal nerve entrapment. J Neurosurg Spine. 2013;19(1):76-80.

84. Labat JJ, Robert R, Delavierre D, Sibert L, Rigaud J. Approche symptomatique des douleurs neuropathiques somatiques pelvipérinéales chroniques [Symptomatic approach to chronic neuropathic somatic pelvic and perineal pain]. Prog Urol. 2010;20(12):973-981. French.

85. Vilensky JA, Baltes M, Weikel L, Fortin JD, Fourie LJ. Serratus posterior muscles: anatomy, clinical relevance, and function. Clin Anat. 2001;14(4):237-241.

86. Loukas M, Shoja MM, Thurston T, Jones VL, Linganna S, Tubbs RS. Anatomy and biomechanics of the vertebral aponeurosis part of the posterior layer of the thoracolumbar fascia. Surg Radiol Anat. 2008;30(2):125-129.

87. Hoheisel U, Taguchi T, Treede RD, Mense S. Nociceptive input from the rat thoracolumbar fascia to lumbar dorsal horn neurones. Eur $J$ Pain. 2011;15(8):810-815

88. Kim YE, Choi HW. Paraspinal muscle activation in accordance with mechanoreceptors in the intervertebral discs. Proc Inst Mech Eng H. 2013;227(2):138-147.

89. Jeong YM, Shin MJ, Lee SH, Chung HW. Sagging posterior layer thoracolumbar fascia: can it be the cause or result of adjacent segment diseases? J Spinal Disord Tech. 2013;26(4):E124-E129.

90. Mihalache G, Indrei A, Tăranu T. Les structures antérolatérale du cou et $\mathrm{du}$ tronc [The anterolateral structures of the neck and trunk]. Rev Med Chir Soc Med Nat Iasi. 1996;100(1-2):69-74. Romanian.

91. Kitayama T, Saito T, Iwabuchi T, et al. Anatomical study of the stellate ganglion position, the cervical sympathetic trunk, and the surrounding membrane structures. Anesth Prog. 2011;58(1):43-51.

92. Verjee LS, Midwood K, Davidson D, Eastwood M, Nanchahal J. Post-transcriptional regulation of alpha-smooth muscle actin determines the contractile phenotype of Dupuytren's nodular cells. J Cell Physiol. 2010;224(3):681-690.

93. Minasny B. Understanding the process of fascial unwinding. Int J Ther Massage Bodywork. 2009;2(3):10-17.
94. Martínez Rodríguez R, Galán del Río F. Mechanistic basis of manual therapy in myofascial injuries. Sonoelastographic evolution control. J Bodyw Mov Ther. 2013;17(2):221-234.

95. Tubbs RS, Marshall T, Loukas M, Shoja MM, Cohen-Gadol AA. The sublime bridge: anatomy and implications in median nerve entrapment J Neurosurg. 2010;113(1):110-112.

96. Clavert P, Lutz JC, Adam P, Wolfram-Gabel R, Liverneaux P, Kahn JL. Frohse's arcade is not the exclusive compression site of the radial nerve in its tunnel. Orthop Traumatol Surg Res. 2009;95(2):114-118.

97. Tubbs RS, Deep A, Shoja MM, Mortazavi MM, Loukas M, CohenGadol AA. The arcade of Struthers: An anatomical study with potential neurosurgical significance. Surg Neurol Int. 2012:184.

98. Jinde L, Jianliang S, Xiaoping C, et al. Anatomy and clinical significance of pectoral fascia. Plast Reconstr Surg. 2006;118(7):1557-1560.

99. Stecco C, Gagey O, Macchi V, et al. Tendinous muscular insertions onto the deep fascia of the upper limb. First part: anatomical study. Morphologie. 2007;91(292):29-37.

100. Stecco A, Macchi V, Masiero S, et al. Pectoral and femoral fasciae: common aspects and regional specializations. Surg Radiol Anat 2009;31(1):35-42.

101. Hedley G. Notes on visceral adhesions as fascial pathology. J Bodyw Mov Ther. 2010;14(3):255-261.

102. Bove GM, Chapelle SL. Visceral mobilization can lyse and prevent peritoneal adhesions in a rat model. J Bodyw Mov Ther. 2012;16(1) 76-82.

103. Norton-Old KJ, Schache AG, Barker PJ, Clark RA, Harrison SM, Briggs CA. Anatomical and mechanical relationship between the proximal attachment of adductor longus and the distal rectus sheath. Clin Anat. 2013;26(4):522-530.

104. Morris H. Surgical pathology of the lower uterine segment caesarean section scar: is the scar a source of clinical symptoms? Int J Gynecol Pathol. 1995;14(1):16-20.

105. Marsden NJ, Wilson-Jones N. Scar endometriosis: a rare skin lesion presenting to the plastic surgeon. J Plast Reconstr Aesthet Surg. 2013;66(4):e111-e113.

106. Biswas BK, Gupta N, Magon N. Incisional endometriosis: A rare cause for a painful scar - A report and commentary. Niger Med J. 2012;53(4):257-259.

107. Miranda A, Peles S, Rudolph C, Shaker R, Sengupta JN. Altered visceral sensation in response to somatic pain in the rat. Gastroenterology. 2004;126(4):1082-1089.

108. King HH, Janig W, Patterson MM. The Science and Clinical Application of Manual Therapy. London: Churchill Livingstone Elsevier; 2011.

109. Johnson IP. Colorectal and uterine movement and tension of the inferior hypogastric plexus in cadavers. Chiropr Man Therap. 2012;20(1):13

110. McSweeney TP, Thomson OP, Johnston R. The immediate effects of sigmoid colon manipulation on pressure pain thresholds in the lumbar spine. J Bodyw Mov Ther. 2012;16(4):416-423.

111. Ma WL, Zhang WB, Xiong KH, Guo F. Visceral and orofacial somatic afferent fiber terminals converge onto the same neuron in paratrigeminal nucleus: An electron microscopic study in rats. Auton Neurosci. 2007;131(1-2):45-49.

112. Valouchová P, Lewit K. Surface electromyography of abdominal and back muscles in patients with active scars. J Bodyw Mov Ther. 2009;13(3):262-267.

113. Findley TW, Shalwala M. Fascia Research Congress Evidence from the 100 year perspective of Andrew Taylor Still. J Bodyw Mov Ther. 2013;17(3):356-364.

114. Anastasi et al. AA VV, Anatomia dell'uomo, 4 ed, Edi.ermes, Milano [Human Anatomy]. www.eenet.it. 


\section{Publish your work in this journal}

The Journal of Multidisciplinary Healthcare is an international, peerreviewed open-access journal that aims to represent and publish research in healthcare areas delivered by practitioners of different disciplines. This includes studies and reviews conducted by multidisciplinary teams as well as research which evaluates the results or conduct of such teams or

healthcare processes in general. The journal covers a wide range of areas and welcomes submission from practitioners at all levels, from all over the world. The manuscript management system is completely online and includes a very quick and fair peer-review system. Visit http://www.dovepress.com/testimonials.php to read real quotes from published authors.

Submit your manuscript here: http://www.dovepress.com/journal-of-multidisciplinary-healthcare-journal 